\title{
Trade-off Study of a High Power Density Starter- Generator for Turboprop Aircraft System
}

\author{
M. Raza Khowja, Gaurang Vakil, Chris Gerada, Tao Yang, Serhiy Bozhko, Pat Wheeler \\ Power Electronics, Machine and Control (PEMC) Group \\ The University of Nottingham \\ Nottingham, United Kingdom \\ Raza.Khowja@nottingham.ac.uk, Gaurang.Vakil@nottingham.ac.uk
}

\begin{abstract}
Mechanically-driven actuators, compressors and pumps are being replaced by the aircraft manufacturers that shift the trend towards "More Electric Aircraft" and hence reducing the mechanical linkages within the aircraft system. This elevates the dependence of the electrical power on the main engine, deicing and cabin environmental system which originates from the startergenerator. This paper presents a trade-off study for the design of high-performance starter-generator, surface-mounted permanent magnet machines, considering slot-pole combination, winding configuration and geometrical layout as degrees of freedom while satisfying the output power and strict volume requirements. 18S/12P combination seems a promising candidate for starter generator application which satisfy all the given requirements, giving the output power of $32 \mathrm{~kW}$ at $14 \mathrm{kRPM}$ within the volume of $1407 \mathrm{~cm}^{3}$.
\end{abstract}

Keywords - starter-generator, concentrated windings, distributed windings

\section{INTRODUCTION}

$\mathbf{E}$ lectrically powered motor drive systems are capable of driving electromechanical and electrohydraulic actuators, compressors, pumps and other aircraft counterparts at variable speeds $[1,2]$. Due to an undergoing remarkable growth in the aerospace industry, the future commercial aircraft system offers the benefit of mass and space-saving, fuel-efficient and costeffective, while meeting the reliability and maintainability needs $[3,4]$. To meet these targets, the mechanically-driven actuators, compressors and pumps are being replaced by the aircraft manufacturers thus shifting the trend towards "More Electric Aircraft" and hence reducing the mechanical linkages within the aircraft system $[4,5]$. This elevates the dependence of the electrical power on the main engine, deicing and cabin environmental system which originates from the startergenerator $[4,6]$. Starter-generator is a twofold functional device which starts the engine by means of external power source from the main DC bus and power the whole electrical distribution network once the engine is started [7].

A conventional starter-generator is a 3-stage brushless synchronous machine which includes: the main generator, preexciter and the main exciter [8]. However, space, mass and its complex control system do not seem to be an appropriate choice for the aircraft avionics system. Therefore, permanent magnet synchronous machines (PMSM) are presently being considered and proven to be a worthy solution for starter-generator in aerospace applications $[4,7,9]$. By Adopting PMSM topology for such applications got rid of field windings and its associated losses, commutator and brush installations which ultimately raises the power density, reliability, device efficiency and reduces the cooling requirements [7]. This trade-off study will focus on the design of a starter-generator based on surfacemounted permanent magnet synchronous machine (SPM) with slot-pole combinations, winding configurations and geometrical layout as degrees of freedom, while satisfying high power density and given space requirements within the limited DC bus voltage. In section II, design requirements and limitations are highlighted. The selection of degrees of freedom and the machine design process is described in section III. Trade-off analysis of the electrical machine is presented in section IV followed by the conclusive remarks in section $\mathrm{V}$.

\section{DESIGN REQUIREMENTS AND LIMITATIONS}

The design of a starter-generator $(\mathrm{S} / \mathrm{G})$ is required to integrate inside the propeller housing as shown in Fig. 1(a) which must satisfy the torque-speed characteristic given in Fig. 1(b). S/G feeds into a $540 \mathrm{~V}$ DC bus which at least delivers $20 \mathrm{~kW}$ at $18 \mathrm{kRPM}$ generation mode and at least $30 \mathrm{~kW}$ at $14 \mathrm{kRPM}$ starting mode while satisfying the given space requirements as illustrated in Table I. The machine operates as a motor during the engine-starting period and must supply the constant torque from standstill to $\mathrm{w}_{\text {rated. }}$. The $\mathrm{S} / \mathrm{G}$ must deliver the output power of at least $30 \mathrm{~kW}$ in the motoring mode. Once the engine is started, the machine switches to its generation mode to supply a minimum of $20 \mathrm{~kW}$ power at $18 \mathrm{kRPM}$ to power the electrical distribution network of the aircraft system.

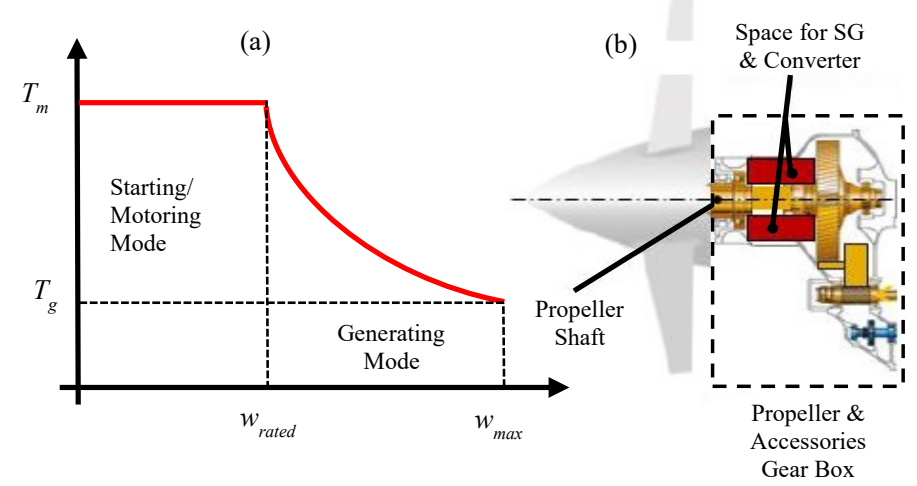

Fig. 1. Turboprop Aircraft System (b) Propeller Accessories \& Gear Box 
The machine must have two 3-phase channels to bring reliability into the system. Each channel must deliver at least $10 \mathrm{~kW}$ mechanical power at $18 \mathrm{kRPM}$ and $15 \mathrm{~kW}$ at $14 \mathrm{kRPM}$ which is connected to a $540 \mathrm{~V}$ DC-link bus. The maximum allowable winding temperature is limited to $180 \mathrm{C}$. The engine oil at $50^{\circ} \mathrm{C}$ is available as a coolant through the stator slots with a flow rate of 5 liters per min. The space for the machine is restricted to $170 \mathrm{~mm}, 91 \mathrm{~mm}$ and $68 \mathrm{~mm}$ as outer diameter, inner diameter and the axial length of the machine respectively, including end windings overhang and housing width on both sides.

TABLE I. Design Details of The StARTER-GENERATOR

\begin{tabular}{l|c|c}
\hline \multicolumn{1}{c|}{ PARAMETERS } & VALUE & UNIT \\
\hline No. of Channels (Star Connections) & $2 \times 3$ phase & - \\
\hline Max. Allowable Winding Temperature & 180 & Celcius \\
\hline Output Power at 14kRPM (both channels) & $>30$ & $\mathrm{~kW}$ \\
\hline Output Power at 18kRPM (both channels) & $>20$ & $\mathrm{~kW}$ \\
\hline DC-Link Voltage & 540 & $\mathrm{~V}$ \\
\hline Rated Speed & 14000 & $\mathrm{RPM}$ \\
\hline Maximum Speed & 18000 & $\mathrm{RPM}$ \\
\hline Outer Diameter & 170 & $\mathrm{~mm}$ \\
\hline Inner Diameter & 91 & $\mathrm{~mm}$ \\
\hline Available Length for Machine & 68 & $\mathrm{~mm}$ \\
\hline Coolant Fluid & Engine Oil & - \\
\hline Coolant Temperature & 50 & Celcius \\
\hline Fluid Flow Rate & 6 & $\mathrm{Ltr} / \mathrm{min}$ \\
\hline \hline
\end{tabular}

\section{MACHINE DESIGN}

\section{A. Pre-Design Process}

Based on the application requirements provided previously, a number of machines were considered, with a range of slot pole combinations for both distributed and concentrated windings. The SPM electrical machine topology is considered for this application due to high power density and the strict volume requirements. By Adopting PMSM topology for such applications got rid of field windings and its associated losses, commutator and brush installations which eventually raises the power density, power-to-volume ratio, reliability, device efficiency and reduces the cooling requirements [7].

Non-oriented electrical steel (JFE_10JNEX900) was considered for stator laminations due to its excellent low iron loss profile and high magnetic flux density properties [10]. For the permanent magnet material, Samarium Cobalt (Recoma 33E) was chosen from Arnold Magnetics due to its highest stability and magnetic output at elevated temperatures as compared to neodymium permanent magnets $(\mathrm{NdFeB})[11]$.

\section{1) Selection of Slot \& Pole Number}

Stator slots for an electrical machine usually range from to 9 to 72 however, limitation comes from a manufacturing point of view if slot constructed beyond 36 slots. Therefore, 9 to 36 slots are considered in this trade-off study. Pole number influence the operating frequency of the machine for a given speed. High pole number increases the power density of the machine but at the same time raises the fundamental frequency requirements for the power converter. The frequency-dependent losses inside the machine also increase with high pole number which leads to higher iron losses at high speeds [12].

However, low pole number will result in low power density by increasing the need of phase current for a given power which leads to low device efficiency and hence increases the cooling requirements to take the heat out of the machine. Therefore, pole number from 8 to 12 is considered in the trade-off analysis [13].

\section{2) Selection of Stator Windings}

It is common practice to use concentrated and distributed winding configuration to wound the stator of the electrical machine. Both winding configurations have its benefits and downsides and the selection of it is application-specific [13].

Concentrated wound $(\mathrm{CW})$ machines are wound in the adjacent slots to form a single coil. Due to its simple manufacturing process, stator laminations can be constructed with segmentation which leads to higher slot fill factor and hence reduced DC phase resistance. Since the windings are wound in the adjacent slots, the end-windings overhang is fairly reduced as compared to distributed windings and hence commonly adopted for the applications where space is of major concern. However, these pros come at the expense of higher space harmonics which lead to an increase in torque ripple, frequency-dependent fundamental and parasitic losses at high speeds $[13,14]$.

On the other hand, distributed wound machines (DW) are wound in the multiple tooth which is not adjacent and hence coil throw becomes more than 1 . Since the windings are sinusoidally distributed, it induces negligible space harmonics in the airgap [13]. The distributed nature of this winding carries more endwinding volume apart from the active part of the machine and hence increases the power-to-volume ratio [13]. This will result in a longer machine for the same active stack length which leads to a poor rotor dynamic response, higher conductor losses and escalates complexity in the manufacturing process [14].

Since both winding configurations have its pros and cons, 3 machines from each configuration are chosen for trade-off analysis which will be investigated in the next sections. In order to get a high power density, the machines with the highest winding factor [13] are chosen for all the slot-pole combination as illustrated in Table II. Due to shorter end-windings overhang, all considered machines are in the double-layer arrangement in order to meet the envelope constraint given to us.

TABLE II. TABLE OF Selected MAchines

\begin{tabular}{l|c|c}
\hline $\begin{array}{c}\text { SELECTED } \\
\text { MACHINES }\end{array}$ & $\begin{array}{c}\text { WINDING } \\
\text { CONFIG. }\end{array}$ & $\begin{array}{c}\text { WINDING } \\
\text { FACTOR }\end{array}$ \\
\hline $24 \mathrm{~S} / 8 \mathrm{P}$ & $\mathrm{DW}$ & 1.0 \\
\hline $30 \mathrm{~S} / 10 \mathrm{P}$ & $\mathrm{DW}$ & 1.0 \\
\hline $36 \mathrm{~S} / 12 \mathrm{P}$ & $\mathrm{DW}$ & 1.0 \\
\hline $9 \mathrm{~S} / 8 \mathrm{P}$ & $\mathrm{CW}$ & 0.945 \\
\hline $12 \mathrm{~S} / 10 \mathrm{P}$ & $\mathrm{CW}$ & 0.933 \\
\hline $18 \mathrm{~S} / 12 \mathrm{P}$ & $\mathrm{CW}$ & 0.866 \\
\hline \hline
\end{tabular}

A twofold double layer winding arrangement is implemented for all the slot-pole combinations illustrated in Table II. This provides 2-star channels which are connected to the $540 \mathrm{~V}$ common DC-link. Each of the 3-phase winding is 
separated electrically and physically. The physical separation is achieved by creating a gap between the phase coils which ensures there is no physical contact between the phases of star connections. The electrical twofold star connections are shown in Fig. 2(a). In this analysis, both channels are connected in series to investigate the machine's study as a whole as illustrated in Fig. 2(b). This will change the DC-link to $1080 \mathrm{~V}$ which gives the maximum limit of $440 \mathrm{~V}$ phase RMS voltage on the motor terminals.

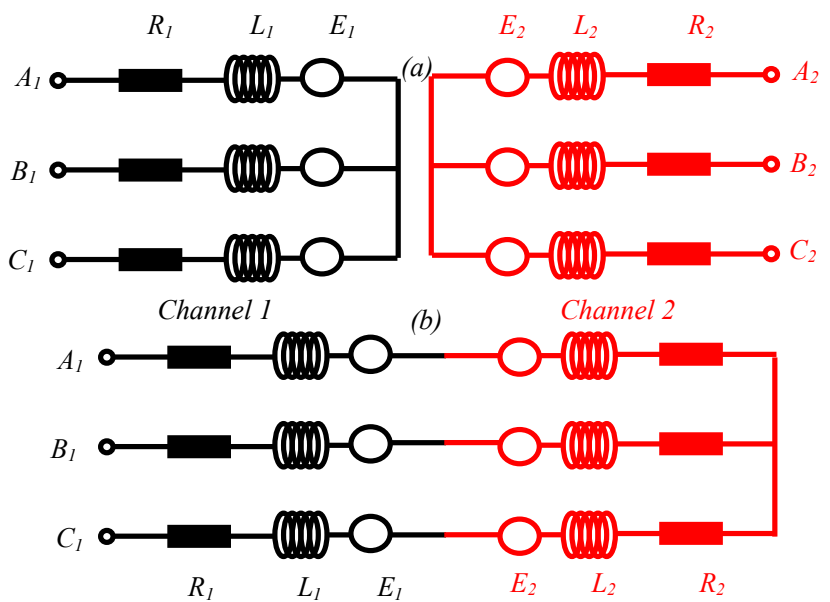

Fig. 2. 2-Star Winding Arrangement

\section{3) Selection of Cooling System}

In general, the electrical machine is either use air or fluid to take the heat out. For air-cooled machines by natural convection, the current density of the stator conductor is usually varied from 4 to $6 \mathrm{~A} / \mathrm{mm}^{2}$. However, for fluid coolant by forced convection, it can go up to $25 \mathrm{~A} / \mathrm{mm}^{2}$ depending on the coolant temperature and flow rate. The available cooling system given for this application are:

- Natural Convention through air

- Forced Air-Coolant temperature is $100 \mathrm{C}$

- Engine Oil - Coolant temperature is 50C

After careful consideration, the oil cooling system is adopted where oil is passing through a gap between the stator conductors. The gap is created by reducing the slot fill factor. The fluid flow rate is 6 liters/min. High power density and strict space requirement do not allow to adopt the air and oil cooling system which limits the current density of the conductor to a lower value and hence lead to lower power density and bigger machine.

\section{B. Design Process}

The machines were designed in Motor-CAD software package [15]. In the design process, tooth width $\left(\mathrm{T}_{\mathrm{w}}\right)$, slot depth $\left(S_{d}\right)$, stator bore diameter $\left(D_{\text {bore }}\right)$, slot number, pole number, magnet thickness $\left(\mathrm{M}_{\mathrm{t}}\right)$ and the number of turns per phase $\left(\mathrm{N}_{\mathrm{ph}}\right)$ were considered as geometrical degrees of freedom. Table III shows the machine design parameters that have been kept the same for each machine. The stack length was fixed to $32 \mathrm{~mm}$ knowing fact that the total axial length is limited to $68 \mathrm{~mm}$ including end-windings overhang and housing width. This will avoid the poor dynamic response of the rotor as discussed in the previous section. Moreover, $4 \mathrm{~mm}$ space on both side was added as the clearance between the end-windings and the housing wall.

The tooth and back iron flux density was also fixed to $1.5 \mathrm{~T}$ by varying its cross-section area along with the slot opening, slot opening height and the airgap between stator and rotor as $2.5 \mathrm{~mm}, 1 \mathrm{~mm}$ and $4 \mathrm{~mm}$ respectively. The stator and rotor sleeves of $1 \mathrm{~mm}$ and $2 \mathrm{~mm}$ were considered leaving the actual airgap of $1 \mathrm{~mm}$. "Continuous Ring Array" Halbach rotor was considered with $60^{\circ}$ central magnet arc, $180^{\circ}$ magnet arc and 3 magnet segmentation per pole.

TABLE III. MAChine DeSIGn PARAMETERS

\begin{tabular}{l|c|c}
\hline \multicolumn{1}{c|}{ PARAMETERS } & VALUE & UNIT \\
\hline Average Winding Temperature & $\approx 150$ & Celcius \\
\hline Motor Terminal Voltage (Rated) & 420 & $\mathrm{~V}_{\text {ph-rms }}$ \\
\hline Modulation Index & 0.95 & - \\
\hline Loss Build Factor & 2 & - \\
\hline Tooth And Back Iron Flux Density & 1.5 & $\mathrm{~T}$ \\
\hline Slot Fill Factor & 0.4 & - \\
\hline Stator Outer Diameter & 160 & $\mathrm{~mm}$ \\
\hline Shaft Outer Diameter & 91 & $\mathrm{~mm}$ \\
\hline Machine's Stack Length & 32 & $\mathrm{~mm}$ \\
\hline Stator Sleeves & 1 & $\mathrm{~mm}$ \\
\hline Airgap & 1 & $\mathrm{~mm}$ \\
\hline Rotor Sleeves & 2 & $\mathrm{~mm}$ \\
\hline Magnet Arc & 180 & Degrees \\
\hline Central Magnet Arc & 60 & Degrees \\
\hline \hline
\end{tabular}

TABLE IV. GEOMETRICAL DEgREES OF FREEDOM

\begin{tabular}{c|c|c|c|c|c|c|c}
\hline \hline $\begin{array}{c}\mathbf{M} \\
\#\end{array}$ & $\begin{array}{c}\text { SLOT/ } \\
\text { POLE }\end{array}$ & $\begin{array}{c}\mathbf{T}_{\mathbf{w}} \\
(\mathbf{m m})\end{array}$ & $\begin{array}{c}\mathbf{S}_{\mathbf{d}} \\
(\mathbf{m m})\end{array}$ & $\begin{array}{c}\mathbf{D}_{\text {bore }} \\
(\mathbf{m m})\end{array}$ & $\begin{array}{c}\mathbf{M}_{\mathbf{t}} \\
(\mathbf{m m})\end{array}$ & $\mathbf{N}_{\mathbf{p h}}$ & $\begin{array}{c}\mathbf{I}_{\text {ph-rms }} \\
(\mathbf{A})\end{array}$ \\
\hline $\mathrm{M} 1$ & $9 \mathrm{~S} / 8 \mathrm{P}$ & 14.5 & 14.3 & 108.5 & 4.70 & 138 & 28.3 \\
\hline $\mathrm{M} 2$ & $12 \mathrm{~S} / 10 \mathrm{P}$ & 12.0 & 15.3 & 116.5 & 8.70 & 140 & 30.0 \\
\hline $\mathrm{M} 3$ & $18 \mathrm{~S} / 12 \mathrm{P}$ & 9.0 & 14.0 & 122.5 & 11.7 & 144 & 31.0 \\
\hline $\mathrm{M} 4$ & $24 \mathrm{~S} / 8 \mathrm{P}$ & 5.5 & 15.7 & 118.0 & 9.40 & 140 & 27.0 \\
\hline $\mathrm{M} 5$ & $30 \mathrm{~S} / 10 \mathrm{P}$ & 6.0 & 13.5 & 121.5 & 11.0 & 130 & 26.8 \\
\hline $\mathrm{M} 6$ & $36 \mathrm{~S} / 12 \mathrm{P}$ & 5.5 & 12.5 & 124.5 & 12.7 & 120 & 28.0 \\
\hline \hline
\end{tabular}

Build factor of 2 was assumed for both iron and copper losses to give a safety margin. The copper build factor was added by increasing its resistivity by twice. This will take into account of AC loss due to proximity and skin effects. The slot factor fill was kept to 0.4 to ensure the space required for coolant to flow between the conductors.

The modulation index of 0.95 is fixed which gives the limit OF $420 \mathrm{~V}$ for phase RMS motor terminal voltage. The magnet thickness, number of turns per phase and the phase current is adjusted simultaneously until the rated voltage $\left(420 \mathrm{~V}_{\text {ph-rms }}\right)$ is reached at rated rotor speed (14kRPM). Moreover, the field weakening is introduced until 18kRPM to keep the motor voltage at its rated value $\left(420 \mathrm{~V}_{\mathrm{ph}-\mathrm{rms}}\right)$.

For the purpose of a fair comparison, the value of phase current $\left(\mathrm{I}_{\mathrm{ph}-\mathrm{rms}}\right)$ is adjusted until the average winding temperature reaches $150 \mathrm{C}$, which gives the safety margin of $30 \mathrm{C}$. All the assumptions and parameters that were kept fixed during the design process are indicated in Table II, whereas the geometrical degrees of freedom that was adjusted for each of the selected slot-pole combinations are illustrated in Table IV. 
Since the airgap and shaft outer diameter is fixed the bore diameter and slot depth is varied such that the average winding temperature does not exceed $150 \mathrm{C}$ and back iron flux density remain under $1.5 \mathrm{~T}$ in order to avoid deep magnetic saturation which leads to lower d-axis inductance. This left the magnet thickness as a function of the stator bore diameter. In this case, higher the stator bore diameter will leads to higher magnet thickness which requires lower electrical loading $\left(\mathrm{N}_{\mathrm{ph}} \times \mathrm{I}_{\mathrm{ph}-\mathrm{rms}}\right)$.

\section{TRADE-OFF ANALYSIS}

\section{A. Effect of Slot-pole Combinations on Power Factor}

The effect of changing slot-pole combination is discussed here. The variation of power factor at 14 and $18 \mathrm{kRPM}$ and $\mathrm{d}-\mathrm{q}$ inductance w.r.t slot number is illustrated in Fig 3(a). As can be seen from Fig. 3(a), the d-q inductance (and hence phase inductance) is decreasing as the slot number is increased. This affects the power factor of the machine at both rated and maximum speed. As expected, the power factor is improved as the slot number is increased and $\mathrm{d}-\mathrm{q}$ inductance is decreased. This is due to the dependence of the power factor on the inductance of the machine. The variation of current angle (phase advance) required to keep the motor terminal voltage within the permissible DC-link limit is shown in Fig. 3(b). It can be seen that the machine with higher slot number requires large d-axis current to limit the motor voltage due to the lower d-axis inductive voltage drop $\left(\mathrm{I}_{\mathrm{d}} \times \mathrm{X}_{\mathrm{d}}\right)$.
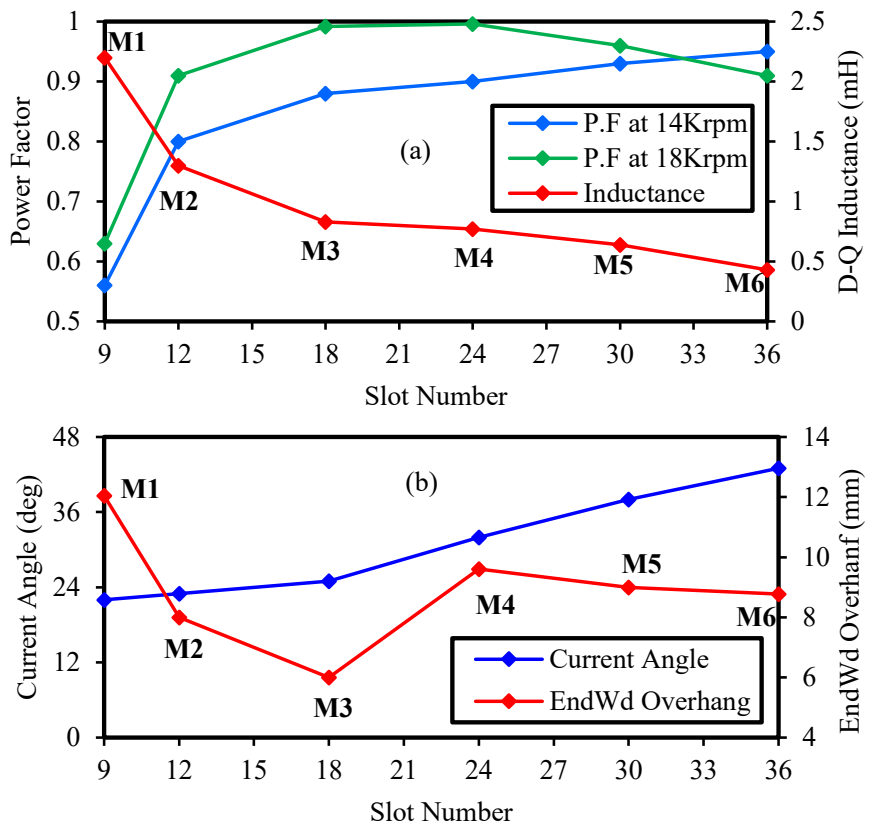

Fig. 3. Effect of Changing Slot Number (a) Power Factor and Inductance variation (b) Current Angle and EndWd Overhang

End windings overhang is calculated using the method explained in paper [16] and Fig. 4. It is clear that the double layer CW occupied the lowest end windings overhang when compared to single-layer $\mathrm{CW}$ and DW. The calculation of end windings overhang for a double layer winding is given as:

$$
\begin{gathered}
O H_{c w}=L \times d \\
O H_{d w}=1.5 \times L \times d
\end{gathered}
$$

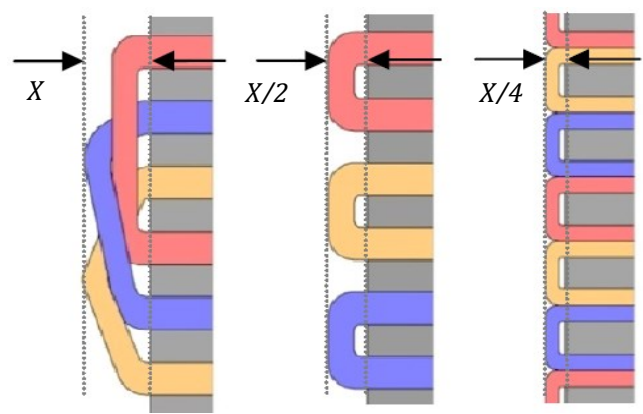

Fig. 4. EndWd Overhang Calculation (Fig. 7 of [16])

Where $\mathrm{L}$ is the number of conductor layers and $\mathrm{d}$ is the wire diameter. It is worth noting that the machine with a unity factor will produce the maximum output power with improved efficiency. Two combinations i.e. $18 \mathrm{~S} / 12 \mathrm{P}$ and $24 \mathrm{~S} / 8 \mathrm{P}$ giving approximately unity power factor at $18 \mathrm{kRPM}$.

\section{B. Torque and Power Speed Characteristic}

The output torque and power speed characteristics of the selected machines are shown in Fig. 5(a) and Fig. 5(b) respectively. As per requirement, machines developed the constant output torque until the rated voltage and speed is reached. Afterwards, d-axis current is injected to limit the converter KVA rating.
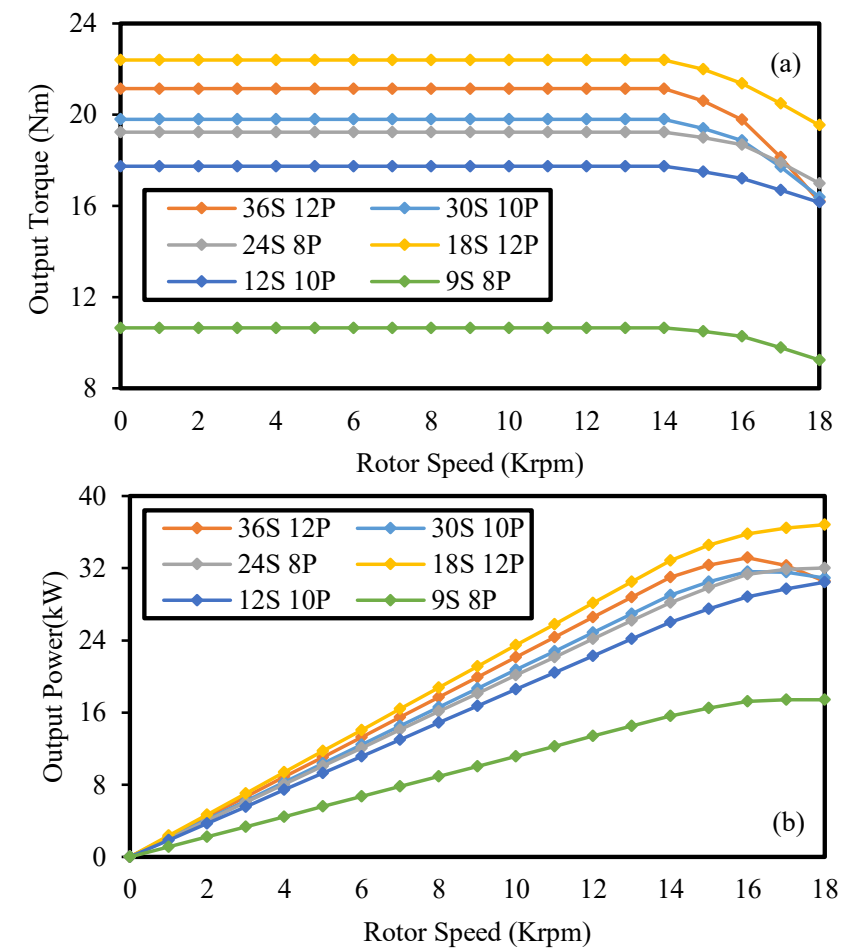

Fig. 5. Torque and Power Speed Characteristics (a) Torque-speed curve (b) Power-speed curve

As expected, 18S 12P combination gives the highest output power due to the unity power factor at $18 \mathrm{kRPM}$ with highest electrical loading amongst all (Table IV), for a given average winding temperature $(\approx 150 \mathrm{C})$. $36 \mathrm{~S} 12 \mathrm{P}$ is the second most candidate which deliver the highest output power in the constant torque region whereas $24 \mathrm{~S} 8 \mathrm{P}$ gives the highest output power at 
$18 \mathrm{kRPM}$ after $18 \mathrm{~S} 12 \mathrm{P}$ machine after $18 \mathrm{~S} 12 \mathrm{P}$ combination. On the other hand, the 9S $8 \mathrm{P}$ combination is unable to provide the required amount of output power.

\section{Efficiency}

Fig. 6(a) shows the efficiency vs speed curve of all the electrical machines considered for the trade-off study. It can be seen that the trend of the efficiency curve follows the output power of the machine as illustrated in Fig. 5(b). As expected, $18 \mathrm{~S} 12 \mathrm{P}$ combination is giving the highest efficiency at all operating points including field weakening region whereas the efficiency of 36S 12P combination falls as it goes into the field weakening region due to leading power factor. On the other hand, 9S 8P candidate gives the lowest efficiency due to the low pole number and hence lower output power production.

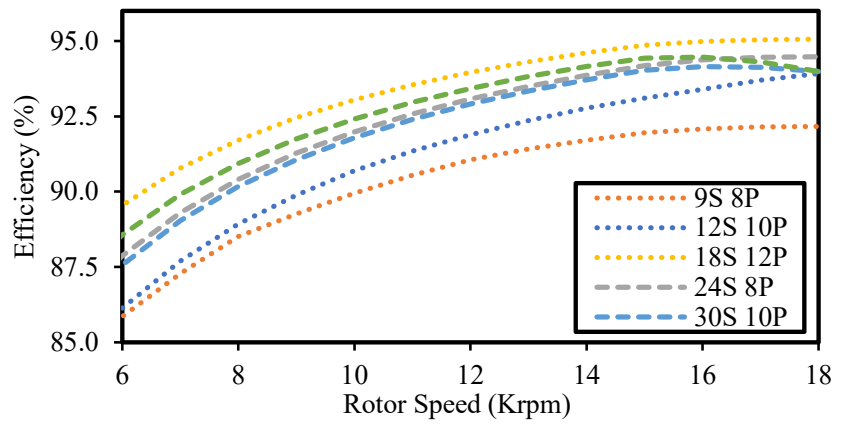

Fig. 6. Efficiency of all slot-pole combinations

\section{Losses \& Temperature}

The total losses and the winding temperature of all the machines have been discussed in this section. Fig. 7(a) shows the DC copper loss and iron loss of the machine. The copper loss is constant throughout rotor speed as the built factor 2 was assumed to take AC loss into account due to proximity and skin effects. The iron loss at 18kRPM is considered here as the authors have investigated that the highest iron losses occur at this operating point. The mechanical losses have not been included in the total power losses as these were assumed to be very similar for the selected designs and hence were not critical for this trade-off analysis. From Fig. 7(b), it can be seen that the machine with 9S 8P combination produces the lowest copper loss but gives the lowest efficiency at the same time, therefore, power loss must not only be compared between the considered machine designs for the trade-off study. The phase resistance and phase current drawn by each machine are shown in Fig. 7(b) which produces the copper loss in Fig. 7(a). On the other hand, the iron loss seems to be very similar for all the machine designs since the active stack length and core flux density was fixed in the design process. The mean and peak winding temperature of the considered machine designs are shown in Fig. 7(c). The mean winding temperature is adjusted to $150 \mathrm{C}$ in the design process to have a fair comparison. The peak winding temperature is relatively higher than the mean temperature which occurs at the end windings. This is due to the insufficient cooling available at the end windings overhang as the coolant is only passing through the stator slots. Nevertheless, the machine with $18 \mathrm{~S} 12 \mathrm{P}$ gives the highest peak winding temperature which is still under the maximum allowable limit of the winding insulation class.
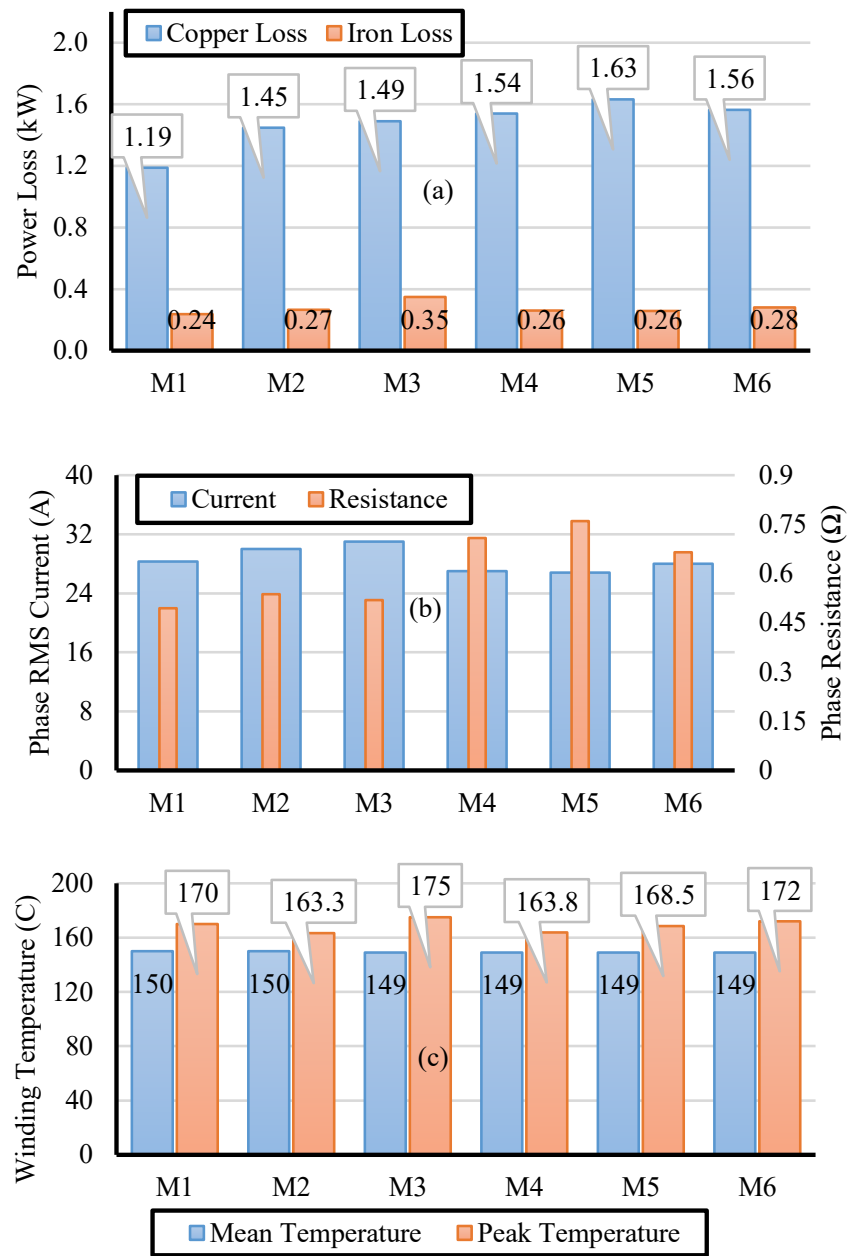

Fig. 7. Losses and Winding Temperature (a) Copper and Iron Loss (b) Phase RMS Current and Phase Resistance (c) Mean and Peak Winding Temperature

\section{E. Total Machine Length}

The comparison of the total machine length is compared in order to check which machine meet the space constraints as shown in Fig. 7. The active length was fixed to $32 \mathrm{~mm}$ and $4 \mathrm{~mm}$ space was added as the clearance between the end-windings and the housing wall on both sides. The housing width was fixed to $4 \mathrm{~mm}$ each side. As can be seen from Fig. 7 that only 3 machines have met the space requirements (12S, $18 \mathrm{~S}$ and $36 \mathrm{~S})$ on the space limit contour of $68 \mathrm{~mm}$, whereas two machines (9S and 24S) were unable to meet the space requirement. On the other hand, the $30 \mathrm{~S}$ machine exactly lies on the limit contour.

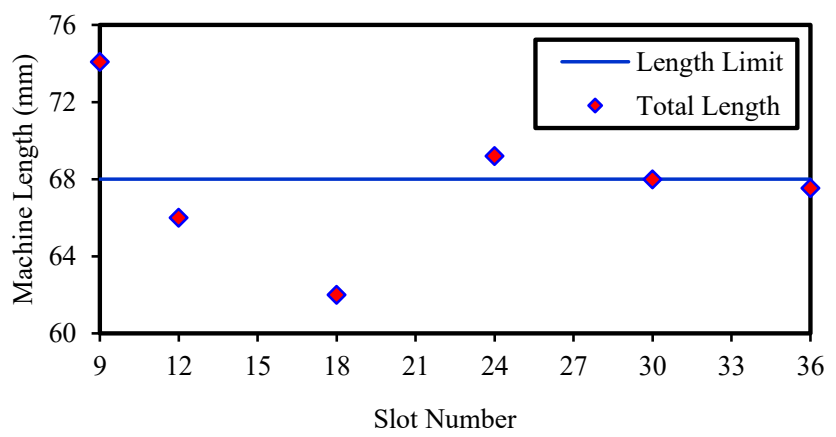

Fig. 8. Total Machine Length 


\section{F. Selection of the Machine - Trade-off Choice}

Both machines (18S and 36S) have met the output power and space requirement. The $18 \mathrm{~S}$ and $36 \mathrm{~S}$ machine delivers $32.8 \mathrm{~kW}$ and $31 \mathrm{~kW}$ at $14 \mathrm{kRPM}$ and $36.8 \mathrm{~kW}$ and $31 \mathrm{~kW}$ at $18 \mathrm{kRPM}$ whilst occupying the total length of $62 \mathrm{~mm}$ and $67.5 \mathrm{~mm}$ respectively. In terms of efficiency, 18S 12P machine is again superior to the $36 \mathrm{~S} 12 \mathrm{P}$ machine. Moreover, 36S 12P machine requires more daxis current at $18 \mathrm{kRPM}$ to keep the rated voltage within the permissible limit as opposed to $18 \mathrm{~S}$ machine. The DW machine (36S) gives the larger end windings overhang than CW machine (18S) which increases its phase resistance and hence resulted in a higher copper loss. Since the $18 \mathrm{~S}$ machine is the shortest and efficient, therefore, it has been selected for this application. In terms of cost, $18 \mathrm{~S} 12 \mathrm{P}$ machine will be cheaper to manufacture from a financial point of view as it requires less PM mass and delivers more output power as compared to a 36S 12P machine. When comparing the machine's cost based on the manufacturing time, both rotors will have similar requirements but the $18 \mathrm{~S} 12 \mathrm{P}$ stator will be easier to manufacture as it can be constructed in the segmented tooth, giving the higher slot fill factor.

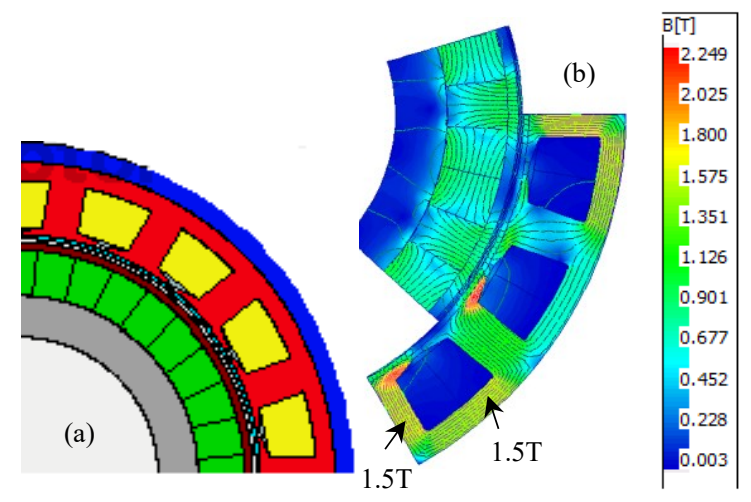

Fig. 9. Selected Machine (a) radial cross-section (b) field distribution

\section{CONCLUSION}

Different slot-pole combinations have been compared in this paper based on their potential to satisfy the given output power and envelop requirements. The slot-pole combination, winding configuration and geometrical layout were considered as degrees of freedom in the analysis. The comparative analysis showed 12 to be an optimal pole number, because it was seen to be the best trade-off between the fundamental frequency, output power and the envelope. It was shown that the change in slotpole combinations affect the power factor of a particular machine and hence affect the output power and efficiency. 18S $12 \mathrm{P}$ and $24 \mathrm{~S} 8 \mathrm{P}$ were found to produce the unity power factor at $18 \mathrm{kRPM}$ which has ultimately increased the power and efficiency at this speed. Also, the increase in slot number increases the d-axis current requirement at 18kRPM due to the change in the $\mathrm{d}$-axis inductance to maintain the motor voltage within the allowable DC-link. From the power-speed characteristics point of view, $18 \mathrm{~S} 12 \mathrm{P}$ and $36 \mathrm{~S} 12 \mathrm{P}$ machines were producing the highest output power in the constant torque region, while $18 \mathrm{~S}$ machine was superior to $36 \mathrm{~S}$ machine. $18 \mathrm{~S} / 12 \mathrm{P}$ combination looked to be a promising candidate in terms of delivering output power at both rated and maximum speed. $18 \mathrm{~S}$ machine was able to deliver $32 \mathrm{~kW}$ at $14 \mathrm{kRPM}$ with the total machine length of $62 \mathrm{~mm}$, which is the shortest amongst all combinations. From an efficiency point of view, the $18 \mathrm{~S}$ machine is again a better candidate than the $36 \mathrm{~S}$ machine due to higher current loading for a given space and a better power factor at $18 \mathrm{kRPM}$. On the other hand, the $36 \mathrm{~S}$ machine was required more d-axis current to keep the converter KVA rating at bay which eventually affects the machine's efficiency.

\section{ACKNOWLEDGEMENT}

This project has received funding from the Clean Sky 2 Joint Undertaking under the European Union's Horizon 2020 research and innovation programme under grant agreement No 737814.

\section{REFERENCES}

[1] C. Gerada and K. J. Bradley, "Integrated PM Machine Design for an Aircraft EMA," IEEE Transactions on Industrial Electronics

[2] W. Cao, B. C. Mecrow, G. J. Atkinson, J. W. Bennett, and D. J. Atkinson, "Overview of Electric Motor Technologies Used for More Electric Aircraft (MEA)," IEEE Transactions on Industrial Electronics

[3] A. Boglietti, A. Cavagnino, A. Tenconi, S. Vaschetto, and P. d. Torino, "The safety critical electric machines and drives in the more electric aircraft: A survey," in 2009 35th Annual Conference of IEEE Industrial Electronics, 2009, pp. 2587-2594.

[4] P. Arumugam, Z. Xu, A. L. Rocca, G. Vakil, M. Dickinson, E. Amankwah, et al., "High-Speed Solid Rotor Permanent Magnet Machines: Concept and Design," IEEE Transactions on Transportation Electrification, vol. 2, pp. 391-400, 2016.

[5] P. Giangrande, et al., "Considerations on the Development of an Electric Drive for a Secondary Flight Control Electromechanical Actuator," IEEE Transactions on Industry Applications

[6] V. Madonna, P. Giangrande, and M. Galea, "Electrical Power Generation in Aircraft: Review, Challenges, and Opportunities," IEEE Transactions on Transportation Electrification, vol. 4, pp. 646-659, 2018.

[7] Y. Song, X. Xiao, X. Zou, W. Wang, and C. Tang, "Flux-weakening control for starter-generator system based on high-speed permanentmagnet synchronous machine," in 2017 Chinese Automation Congress (CAC), 2017, pp. 3230-3235.

[8] N. Jiao, W. Liu, J. Peng, S. Mao, and H. Zhang, "Design and control strategy of a two-phase brushless exciter for three-stage starter/generator," in 2014 IEEE Energy Conversion Congress and Exposition (ECCE), 2014, pp. 5864-5869.

[9] P. Arumugam, et al., "Comparative design analysis of Permanent Magnet rotor topologies for an aircraft starter-generator," in 2014 IEEE International Conference on Intelligent Energy and Power Systems (IEPS), 2014

[10] JFE Steels. Available: $\quad$ http://www.jfesteel.co.jp/en/products/electrical/product/n_core.php

[11] Arnold Magnetics. Available: http://www.arnoldmagnetics.com/products/recoma-samarium-cobaltmagnets/

[12] A. Al-Timimy, et al., "Design and Losses Analysis of a High Power Density Machine for Flooded Pump Applications," IEEE Transactions on Industry Applications, vol. 54, pp. 3260-3270, 2018.

[13] A. Walker, et al., "Design considerations for high performance traction machines: Aiming for the FreedomCar 2020 targets," in 2015 International Conference on Electrical Systems for Aircraft, Railway, Ship Propulsion and Road Vehicles (ESARS), 2015, pp. 1-6.

[14] A. Al-Timimy, et al., "Trade-off analysis and design of a high power density PM machine for flooded industrial pump," in IECON 2016 - 42nd Annual Conference of the IEEE Industrial Electronics Society, 2016, pp. 1749-1754.

[15] MotorCAD. Available: https://www.motor-design.com/motor-cadsoftware/

[16] L. Chong, et al., "Comparison of concentrated and distributed windings in an IPM machine for field weakening applications," in 2010 20th Australasian Universities Power Engineering Conference, 2010, pp. 1-5. 